\title{
A screening sampling plan to detect Mycobacterium avium subspecies paratuberculosis-positive dairy herds
}

\author{
A. Serraino, ${ }^{*}$ N. Arrigoni,† F. Ostanello, ${ }^{*}$ M. Ricchi,† G. Marchetti, ${ }^{*}$ P. Bonilauri,ł E. Bonfante, ${ }^{\star}$ \\ and F. Giacometti*1 \\ *Department of Veterinary Medical Sciences, University of Bologna, Via Tolara di Sopra 50, 40064 Ozzano Emilia (BO), Italy \\ †National Reference Centre for Paratuberculosis, Experimental Institute for Zooprophylaxis in Lombardy and Emilia-Romagna, \\ Strada della Faggiola 1, 29027 Gariga di Podenzano (PC), Italy \\ ‡Institute for Zooprophylaxis in Lombardy and Emilia-Romagna, Via Pitagora 2, 42100 Reggio Emilia, Italy
}

\begin{abstract}
Mycobacterium avium ssp. paratuberculosis (MAP) is the etiological agent of paratuberculosis, a chronic contagious bacterial disease primarily affecting dairy cattle. Paratuberculosis represents a dual problem for the milk production chain: in addition to economic losses to affected herds, MAP may have zoonotic potential. Infected herds must be identified in order to implement programs designed to reduce the incidence of disease within and between herds and to prevent MAP from entering the food chain. The objective of this study was to evaluate the sensitivity and specificity of a screening sampling plan (SSP) to detect MAP-positive dairy herds by repetitive analysis of bulk tank milk (BTM) samples by ELISA and in-line milk filter (ILMF) samples by PCR. Samples from BTM and ILMF were collected twice from 569 dairy herds in southern Italy. Additionally, 12,016 individual milk samples were collected: 9,509 from 102 SSP-positive herds (SSP MAP-positive) and 2,507 from 21 randomly selected SSP-negative herds (SSP MAP-negative). There was a total of 126 SSP MAP-positive herds (i.e., 21.3\% SSP MAP-positive herds; 95\% confidence interval $=18.0-24.9)$; the within-herd apparent prevalence (AP) ranged between 0.00 and $22.73 \%$ (mean $6.07 \%$ ). A significant difference in within-herd AP was shown between SSP MAP-positive herds and SSP MAPnegative herds. A highly significant association was shown between the median AP herd status $(>5 \%)$ and positivity to at least one ILMF or BTM sample. The SSP detected a minimum of $56.25 \%$ of low AP herds (AP $\leq 2.0 \%)$ up to a maximum of $100 \%$ of herds with a within-herd AP $\geq 8.0 \%$. Overall, the SSP detected $85.57 \%$ of herds in which at least one individual milk sample was positive by ELISA. The proposed SSP was an inexpensive and useful tool to detect MAP-positive
\end{abstract}

Received December 5, 2013.

Accepted February 14, 2014.

${ }^{1}$ Corresponding author: federica.giacometti3@unibo.it herds with a higher risk of infection diffusion and milk contamination. Although the SSP cannot be used for MAP-free certification of herds, it could be useful to prioritize appropriate control measures aimed at reducing the prevalence of infection in dairy herds and milk contamination.

Key words: paratuberculosis, screening sampling plan, sensitivity, specificity, dairy farm

\section{INTRODUCTION}

Mycobacterium avium ssp. paratuberculosis (MAP) is the etiological agent of paratuberculosis, also known as Johne's disease (JD), a chronic and progressive granulomatous enteritis affecting ruminants, especially dairy cattle, and a variety of domestic and wildlife species (Chiodini et al., 1984; Beard et al., 2001; Kennedy and Benedictus, 2001). Johne's disease is a dual problem for the milk production chain: it causes economic losses associated with reduced milk yield, low reproduction efficiency, premature culling, and decreased cull cow values in affected herds (Good et al., 2009); MAP is also thought to carry a zoonotic risk, on the basis of both clinical and gross lesion similarities between JD and human Crohn's disease (CD) and the PCR evidence of MAP in the gut of CD patients (Chiodini et al., 2012). The exposure of humans to MAP most likely occurs via contaminated milk and milk products (Gill et al., 2011). Mycobacterium avium ssp. paratuberculosis infection is widespread worldwide and its herd-level prevalence in dairy cattle ranges widely from almost 0 to more than 50\% (APHIS, 2008; Good et al., 2009; Nielsen and Toft, 2009; Carter, 2012). Mycobacterium avium ssp. paratuberculosis may contaminate milk through direct excretion or by fecal contamination during milking (Grant, 2005). It has been detected in bulk tank raw milk (Sweeney et al., 1992; Stephan et al., 2002; Slana et al., 2009; Hanifian et al., 2013; Khol et al., 2013) and can survive low-temperature holding $\left(63^{\circ} \mathrm{C}\right.$ for 30 min) and HTST $\left(72^{\circ} \mathrm{C}\right.$ for $15 \mathrm{~s}$ ) pasteurization (Grant et al., 1996; Millar et al., 1996; Sung and Collins, 1998; 
Grant, 2006; Van Brandt et al., 2011). Viable MAP has even been found in commercially pasteurized milk purchased at retail (Grant et al., 2002; Ayele et al., 2005; Ellingson et al., 2005; Cerf et al., 2007; Shankar et al., 2010; Carvalho et al., 2012). Some countries, such as China and Russia, currently require certification on the sanitary status of dairy herds whose milk is used for dairy products they import. For these reasons, several countries, including Italy (Italian Ministry of Health, 2013), have developed voluntary or mandatory plans aimed at controlling or eradicating MAP (Carter, 2012; Khol and Baumgartner, 2012b).

Herds infected with MAP must be identified in order to implement programs designed to reduce the transmission of MAP within and between herds and to prevent MAP from shedding in the environment and entering the food chain (Khol and Baumgartner, 2012a). In this context, knowledge of the MAP infection status of each herd is a key factor in disease control, in addition to permitting informed decisions by risk managers and creating positive conditions for responsible marketing of animals and their products.

The objective of this study was to evaluate the sensitivity and specificity of a screening sampling plan (SSP) to detect MAP-infected dairy herds by repetitive analysis of bulk tank milk (BTM) samples by ELISA and in-line milk filter (ILMF) samples by PCR compared with individual milk sampling of the whole herd. Results are reported according to consensusbased reporting standards for diagnostic test accuracy studies for paratuberculosis in ruminants (Gardner et al., 2011).

\section{MATERIALS AND METHODS}

\section{Collection of Samples for the SSP}

The investigation was conducted from January 2010 to May 2013. A total of 569 dairy herds located in southern Italy were enrolled in the study. Herds were chosen because of their participation in a program for milk quality improvement supported by the Italian Ministry of Agriculture; herds had no history of testing for paratuberculosis and no other activity was performed during the study. According to Italian law, all dairy herds must be free of tuberculosis, and skin testing for Mycobacterium bovis was performed each year. Herds had from 8 to 608 dairy cows (mean: 123); the main breed farmed was Holstein Friesian, although some herds included a small proportion (about 10\%) of Brown Swiss and Jersey. The type of farming was the typical Italian system, in which cows are housed in the barn year-round. Farmers who agreed to participate in the survey formed the study sample of the first phase of the study: to perform an SSP based on 2 samplings (1 BTM and 1 ILMF for each sampling) for each farm performed 6 mo apart; farmers were requested to provide 2 BTM samples and 2 ILMF samples. Veterinary practitioners collected samples in sterile tubes for BTM samples and in sterile stomacher bags for ILMF samples. Samples were transported to 3 different collection points, frozen at $-20^{\circ} \mathrm{C}$ on the day of sampling, and shipped within $15 \mathrm{~d}$ from sampling for analysis by ELISA (BTM samples) and PCR (ILMF samples) to the accredited laboratory of the National Reference Centre for Paratuberculosis [Gariga di Podenzano (PC), Italy]. All samples were analyzed by the same trained person by a blinded procedure.

Herds that completed the SSP (2 ILMF and 2 BTM analyzed) and that had a positive result for at least one of the screening samples were recorded as SSP MAPpositive; herds that performed the complete SSP and had negative results in all screening samples were recorded as SSP MAP-negative. The SSP MAP-positive and negative herds were included in the second phase of the study.

\section{Individual Cow Milk Samples}

In the second phase of the study, farmers of all SSP MAP-positive herds were requested to perform individual milk sampling from all lactating cows in the herd to estimate the within-herd MAP apparent prevalence (AP). In addition, individual milk samples were requested from a random selection of farmers whose herds were SSP MAP-negative. Individual milk samples were collected within 3 mo after the previous positive results in SSP-positive herds, and within 3 mo after the end of the SSP in SSP MAP-negative herds. Individual milk samples were collected, stored, and shipped as previously described for BTM samples. Herds in which at least one positive individual milk sample was detected were recorded as MAP-infected herds.

\section{ELISA Analysis of Milk Samples}

Bulk tank and individual milk samples were tested for antibodies against MAP using a commercially available ELISA kit (ID Screen Paratuberculosis indirect, confirmation test, IDVET, Montpellier, France). According to the manufacturer's instructions, each sample was tested in a coated well (even columns) and in an adjacent noncoated well (odd columns). Results were calculated with respect to the corrected sample optical density (OD) (even well OD - odd well OD). The sampleto-positive $(\mathbf{S} / \mathbf{P})$ ratio value was calculated according to the manufacturer's instructions and was considered positive when it was $\geq 0.15$ for BTM samples and $\geq 0.30$ 
for individual milk samples. The test procedures were accredited according to ISO 17025:2005 (ISO, 2005) at the Italian accreditation body Accredia (Rome, Italy). The test sensitivity and specificity for individual milk samples and BTM samples were reported by Nielsen et al. (2013) and Nielsen and Toft (2014), respectively.

\section{PCR Analysis of ILMF}

The ILMF were aseptically cut into small pieces (about $15 \mathrm{~cm}^{2}$ ), put in filtered stomacher bags with $100 \mathrm{~mL}$ of PBS supplemented with $0.05 \%$ Tween 20 (PBS-Tween 20) and homogenized at $300 \mathrm{rpm}$ for 2 min in a Stomacher 400 Circulator (International PBI, Milan, Italy). Fifty milliliters of homogenate was collected into a Falcon tube and centrifuged at 2,500 $\times$ $g$ for $15 \mathrm{~min}$. The pellet obtained was suspended in 1 $\mathrm{mL}$ of PBS-Tween 20, vortexed, and transferred into a 1.5-mL tube. According to Foddai et al. (2010), 10 $\mu \mathrm{L}$ of MyOne Tosylactivated Dynabeads (Life Technologies, Milan, Italy) coated with biotinylated aMp3 peptide (NYVIHDVPRHPA; Research Biochemicals, Cambridge, UK) and with biotinylated aMptD peptide (GHNHHHQHHRPQ; Research Biochemicals) were added to the suspensions obtained from ILMF and mixed on a Stuart SRT6 rotator (Sigma-Aldrich, Milan, Italy) for $30 \mathrm{~min}$ at $30 \mathrm{rpm}$ at room temperature. The samples were then subjected to magnetic separation for 10 min and washed twice with $1 \mathrm{~mL}$ of PBS-Tween 20 . The magnetic beads were suspended in $300 \mu \mathrm{L}$ of PBSTween 20 and $200 \mu \mathrm{L}$ of sterile water supplemented with $300 \mathrm{mg}$ of glass beads (Sigma; $150-212 \mu \mathrm{m}$ in diameter). The sample was subjected to bead beating in a tissue lyser for $10 \mathrm{~min}$ at $30 \mathrm{~Hz}$. The DNA was then extracted using $200 \mu \mathrm{L}$ of supernatant with the DNeasy Blood and Tissue Kit (Qiagen, Milan, Italy), according to the manufacturer's instructions.
Real-time PCR was performed by targeting sequence IS900 with primers and hydrolysis probe as previously described (Ricchi et al., 2009; Donaghy et al., 2011). The amplification reactions were performed in duplicate for each sample using a StepOne Plus System (Life Technologies) in $20 \mu \mathrm{L}$ of master mix containing a 300 $\mathrm{n} M$ concentration of each primer and a $6 \mathrm{n} M$ concentration of the probe; in the case of discrepant results, the analysis was repeated. An internal positive control (Life Technologies) was also added to avoid false-negative results, and an internal extraction control, consisting of a MAP-spiked and frozen milk sample, was used to evaluate the reproducibility of the reaction. All PCR reactions were performed under the following conditions: 40 cycles of denaturation for $15 \mathrm{~s}$ at $95^{\circ} \mathrm{C}$ and annealing and elongation for $60 \mathrm{~s}$ at $60^{\circ} \mathrm{C}$.

The test procedures on milk were accredited according to ISO 17025:2005 (ISO, 2005) at Accredia with an analytical limit of detection of $25 \mathrm{cfu} / \mathrm{mL}$ of milk; the limit of detection of the analytical procedure performed on ILMF was evaluated by spiking ILMF from a MAP-free dairy herd with 10-fold dilutions of 2 MAP strains (ATCC 19698 strain and field strain IZSLER 917/11, isolated from cow feces in a dairy farm located in Parma, Italy) and was estimated to be 10 to $20 \mathrm{cfu} /$ ILMF (see Table 1).

\section{Statistical Analysis}

Statistical analysis was performed using SPSS software (SPSS Statistics ver. 21; IBM Corp., Chicago, IL) and the Mann-Whitney U-test, $\chi^{2}$ test, and Pearson test. The significance limit was set at $P<0.05$. Only data of herds that performed the complete SSP (2 ILMF and 2 BTM samples) and the individual milk sampling were included in the statistical analysis.

Table 1. Detection limit of real-time PCR in in-line milk filters (ILMF) ${ }^{1}$

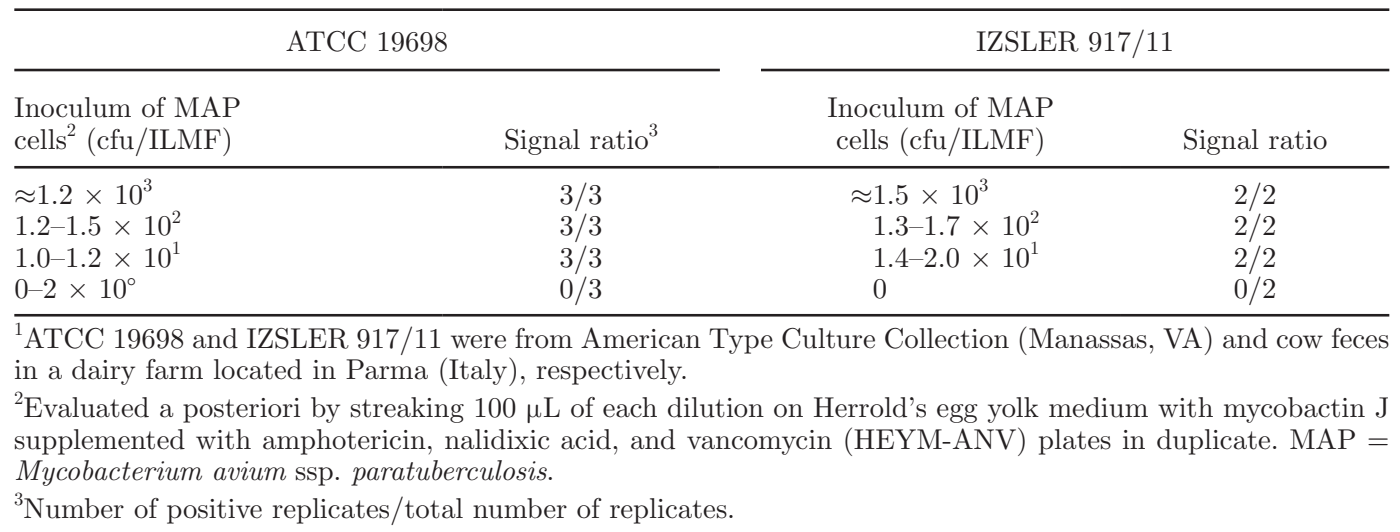


To assess the sensitivity and specificity of the SSP to detect MAP-positive herds, the percentile distribution of the within-herd AP for all herds was calculated. Arbitrarily, herds with an AP value lower than the 25 th percentile, between the 25 th and the 50 th percentile, and between the 50th and the 75th percentile were classified as low, medium, high, respectively; herds with an AP value higher than the 75th percentile were classified as very high. To assess a possible correlation between the $\mathrm{S} / \mathrm{P}$ value of BTM ELISA analysis and the value of within-herd AP, a simple regression was performed and the arithmetic mean of the $\mathrm{S} / \mathrm{P}$ values was used. Equality of variance was tested by plotting the standardized residuals against predicted values and the normality of residuals was examined by a normality probability plot. Confidence intervals were calculated by binomial (Clopper-Pearson) "exact" method based on the $\beta$ distribution.

\section{RESULTS}

\section{SSP}

Bulk tank milk samples were obtained from all 569 herds included in the survey, whereas ILMF samples were collected from a total of 436 herds. The complete SSP (2 BTM samples and 2 ILMF samples) was performed in 385 herds; details are given in Table 2. A total of $121(21.3 \% ; 95 \%$ CI $=18.0-24.9)$ herds were SSP MAP-positive for at least one BTM or one ILMF sample, and repetitive sampling identified more SSP MAP-positive herds than single sampling, both for BTM and for ILMF (see Table 2). The ILMF analysis detected a higher proportion of SSP MAP-positive herds than BTM analysis (18.3 vs. 13.7\%), but none of the tests identified all 121 SSP MAP-positive herds.

\section{Individual Cow Milk Sampling}

In total, 12,016 individual milk samples were collected: 9,509 from 102 SSP MAP-positive and 2,507 from 21 SSP MAP-negative herds. Considering all 126 investigated dairy herds, an overall mean AP of
$6.07 \%$ (range $0.00-22.73 \%$ ) was detected, $1.93 \%$ (range $0.00-2.82 \%$ ) in SSP MAP-negative herds and $6.44 \%$ (range $0.00-22.73 \%$ ) in SSP MAP-positive herds; a significant difference $(P<0.01)$ in within-herd AP was shown between SPP MAP-positive herds and SSP MAP-negative herds.

One hundred seven herds completed the SSP (2 ILMF and 2 BTM samples) and the individual milk sampling, and were therefore considered in the following statistical evaluations. Based on the results of the percentile distribution, herds with AP values of $\leq 2$, $2.1-4.9,5.0-7.9$, and $\geq 8 \%$ were classified as low, medium, high, and very high AP, respectively. No positive individual milk samples were detected in 3 out of 86 SSP MAP-positive herds, whereas some individual milk samples had positive ELISA in 14 out of 21 SSP MAPnegative herds. No significant relationships $(P>0.05)$ were shown between positivity to at least one positive individual milk sample in the herd and positivity to at least one ILMF sample. Likewise, no significant relationship $(P>0.05)$ could be shown between positivity to at least one positive individual milk sample in the herd and positivity to BTM samples. In contrast, a highly significant relationship $(P<0.001)$ was shown between having at least one positive individual milk sample in the herd and positivity to ILMF or BTM samples.

The statistical analysis performed to evaluate the association between the within-herd AP ( $<5 \%$ vs. $\geq 5 \%$ ) and the results of ILMF or BTM analysis disclosed an association between within-herd AP $(\geq 5 \%)$ and a positive BTM ELISA result $(P=0.002)$; the mean $\mathrm{S} / \mathrm{P}$ value of the BTM ELISA test was significantly $(P<0.01)$ related to within-herd AP (Figure 1). The association was not shown for a positive ILMF PCR analysis $(P>$ $0.05)$. A highly significant association $(P=0.001)$ was shown between the median AP herd status $(\geq 5 \%)$ and positivity to at least one ILMF or BTM sample. The data show that repetitive sampling of BTM and ILMF disclosed a higher number of positive farms (from 28.0 to $47.7 \%$ and from 39.3 to $59.8 \%$ for BTM and ILMF respectively), as reported in Table 3 . An association was shown $(P<0.001)$ between within-herd quartile

Table 2. Results of analysis of in-line milk filters (ILMF) by real time-PCR and bulk tank milk (BTM) ELISA performed in the screening sampling plan

\begin{tabular}{|c|c|c|c|c|c|c|c|}
\hline $\begin{array}{l}\text { Sample } \\
\text { analyzed }\end{array}$ & $\begin{array}{l}\text { No. of herds } \\
\text { sampled } \\
\text { (at least once) }\end{array}$ & \multicolumn{2}{|c|}{ First sampling } & \multicolumn{2}{|c|}{ Second sampling } & $\begin{array}{c}\text { Total positive samples } \\
(\% ; 95 \% \text { CI })\end{array}$ & $\begin{array}{l}\text { Total positive herds } \\
\quad(\% ; 95 \% \text { CI })\end{array}$ \\
\hline ILMF & 436 & 413 & $52(12.6 ; 9.5-16.2)$ & 409 & $37(9.0 ; 6.4-12.3)$ & $89(10.8 ; 8.8-13.2)$ & $80(18.3 ; 14.8-22.3)$ \\
\hline BTM & 569 & 554 & $44(7.9 ; 6.0-10.5)$ & 539 & $46(8.5 ; 6.3-11.2)$ & $90(8.2 ; 6.7-10.0)$ & $78(13.7 ; 11.0-16.8)$ \\
\hline Total & & & & & & & $121(21.3 ; 18.0-24.9)$ \\
\hline
\end{tabular}


Table 3. Association between the apparent prevalence (AP) status of the herds and screening sampling plan (SSP) results in the 107 herds in which the complete screening sampling plan [SSP; 2 bulk tank milk (BTM) and 2 in-line milk filter (ILMF) examinations] and individual sampling of cows was performed

\begin{tabular}{lccccc}
\hline & \multicolumn{4}{c}{ Number of herds $(\% ; 95 \%$ CI $)$ positive to } \\
\cline { 2 - 6 } $\begin{array}{l}\text { Within-herd } \\
\text { AP quartile }\end{array}$ & $\begin{array}{c}\text { First BTM } \\
\text { examination* }\end{array}$ & $\begin{array}{c}\text { First or second } \\
\text { BTM examination* }\end{array}$ & $\begin{array}{c}\text { First ILMF } \\
\text { examination }\end{array}$ & $\begin{array}{c}\text { First or second } \\
\text { ILMF examination }\end{array}$ & $\begin{array}{c}\text { Complete } \\
\text { SSP* }\end{array}$ \\
\hline$\leq 2.0 \%$ (low AP) & $1(3.8 ; 0.1-19.6)$ & $2(7.7 ; 0.9-25.1)$ & $4(15.4 ; 4.4-34.9)$ & $11(42.3 ; 23.3-63.1)$ & $12(46.1 ; 26.6-66.6)$ \\
$2.1-4.9 \%$ (medium AP) & $7(25.9 ; 11.1-46.3)$ & $13(48.1 ; 28.7-68.0)$ & $12(44.4 ; 25.5-64.7)$ & $19(70.4 ; 49.8-86.2)$ & $24(88.9 ; 70.8-97.6)$ \\
$5.0-7.9 \%$ (high AP) & $6(23.1 ; 9.0-43.6)$ & $14(53.8 ; 33.4-73.4)$ & $13(50.0 ; 29.9-70.1)$ & $17(65.4 ; 44.3-82.8)$ & $22(84.6 ; 65.1-95.6)$ \\
$\geq 8.0 \%$ (very high AP) & $16(57.1 ; 37.2-75.5)$ & $22(78.6 ; 59.0-91.7)$ & $13(46.4 ; 27.5-66.1)$ & $17(60.7 ; 40.6-78.5)$ & $28(100 ; 87.7-100)$ \\
Total & $30(28.0 ; 19.8-37.5)$ & $51(47.7 ; 37.9-57.5)$ & $42(39.2 ; 29.9-49.2)$ & $64(59.8 ; 49.9-69.2)$ & $86(80.4 ; 71.6-87.4)$ \\
\hline
\end{tabular}

*Significant association between within-herd AP quartile and positivity to SSP examination.

AP and BTM positivity to ELISA test, whereas no association $(P>0.05)$ was observed between withinherd quartile AP and IMLF positivity to PCR. Moreover, a significant association was shown $(P<0.001)$ between within-herd quartile prevalence and BTM or ILMF positivity to ELISA test or to PCR, respectively. Overall, the complete SSP detected a higher number of positive herds than BTM or ILMF examination alone (85.6 of herds in which at least one individual milk sample resulted positive to ELISA). The sensitivity of the complete SSP resulted from a minimum of $56.2 \%$ in low AP herds (AP <2.0\%) up to a maximum of $100 \%$ in herds with a within-herd AP $\geq 8.0 \%$ (Table 4).

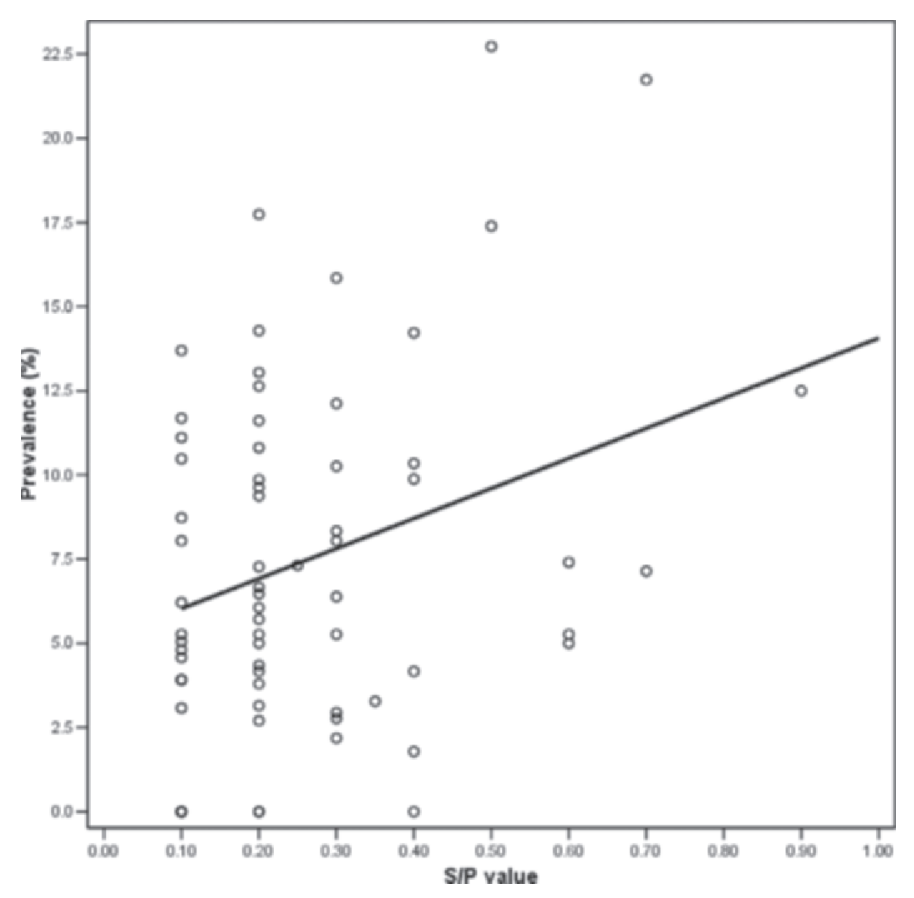

Figure 1. Correlation of mean sample-to-positive $(\mathrm{S} / \mathrm{P})$ value of bulk tank milk ELISA test and within-herd apparent prevalence.

\section{DISCUSSION}

This study reports an SSP for paratuberculosis by BTM or ILMF analysis in 569 dairy herds in southern Italy and its ability to detect MAP-infected dairy herds. Our findings showed that real-time PCR on ILMF detected $18.3 \%$ positive dairy herds compared with $13.7 \%$ detected by ELISA BTM analysis; the disagreement between the 2 tests (PCR and ELISA) was expected because they detect different targets (Wilson et al., 2010).

Regarding the within-herd AP, the fact that some individual milk samples were positive in some SSP-negative herds can be explained by the low sensitivity of the ELISA test used on BTM (30.1\%; 95\% CI: 27.5-37.3\%, as reported by Arrigoni et al., 2007) and the limited sensitivity of the PCR reaction, which detected 10 to $20 \mathrm{cfu} / \mathrm{ILMF}$. The absence of positive individual milk samples in 3 SSP-positive herds can be explained by the fact that individual milk samples were performed 1 to 3 mo after the SSP-positive result (and thus positive cows could have been culled or dried off). The specificity of ILMF for MAP detection was reported to be 100\% (Slana et al., 2012), and a similarly high specificity was reported for ELISA test in BTM (Van Weering et al., 2007) so false-positive results are unlikely.

Positivity to a double sampling of BTM tested by ELISA was significantly related to a within-herd AP $\geq 5 \%$; the mean $\mathrm{S} / \mathrm{P}$ value was significantly correlated to the within-herd AP. The correlation between BTM ELISA results and within-herd AP detected by individual milk sample analysis by ELISA must be interpreted with caution given that, in our study, the within-herd AP was estimated by a single sampling of all lactating cows and thus does not consider the variability due to the lactation stage of individual milk samples (Nielsen and Toft, 2012). Moreover, seasonal variation of MAP antibodies titers in BTM has been reported and related to a higher bacterial load or to seasonal calving practices (Cazer et al., 2013). Considering that the synchronization of calving is not a common practice 
Table 4. Sensitivity and specificity of the screening sampling plan (SSP) compared with ELISA individual milk testing of all lactating cows in the herd

\begin{tabular}{|c|c|c|c|c|c|c|}
\hline \multirow{2}{*}{$\begin{array}{l}\text { Within-herd apparent } \\
\text { prevalence (AP) quartile }\end{array}$} & \multirow[b]{2}{*}{ SSP result } & \multicolumn{2}{|c|}{$\begin{array}{l}\text { Individual milk sampling } \\
\text { result }^{1}\end{array}$} & \multirow[b]{2}{*}{ Total } & \multirow{2}{*}{$\begin{array}{l}\text { Sensitivity, \% } \\
\quad(95 \% \text { CI })\end{array}$} & \multirow{2}{*}{$\begin{array}{l}\text { Specificity, \% } \\
(95 \% \text { CI })\end{array}$} \\
\hline & & Positive & Negative & & & \\
\hline & Negative & 7 & 7 & 14 & \multirow{2}{*}{$56.25(29.88-80.25)$} & \multirow{2}{*}{$70.00(34.75-93.33)$} \\
\hline & Total & 16 & 10 & 26 & & \\
\hline $2.1-4.9 \%$ (medium AP) & Positive & 24 & 0 & 24 & $88.89(70.84-97.65)$ & $\mathrm{NA}^{2}$ \\
\hline \multirow[t]{3}{*}{$5.0-7.9 \%$ (high AP) } & Positive & 22 & 0 & 22 & \multirow[t]{3}{*}{$84.62(65.13-95.64)$} & \multirow[t]{3}{*}{ NA } \\
\hline & Negative & 4 & 0 & 4 & & \\
\hline & Total & 26 & 0 & 26 & & \\
\hline \multirow[t]{3}{*}{$\geq 8 \%($ very high $\mathrm{AP})$} & Positive & 28 & 0 & 28 & \multirow[t]{3}{*}{$100(87.66-100)$} & \multirow[t]{3}{*}{ NA } \\
\hline & Negative & 0 & 0 & 0 & & \\
\hline & Total & 28 & 0 & 28 & & \\
\hline Total & Positive & 83 & 3 & 86 & $85.57(76.97-91.88)$ & $70.00(34.75-93.33)$ \\
\hline
\end{tabular}

${ }^{1}$ Positive if at least one positive sample was detected by individual milk sampling of all the lactating cows in the herd.

${ }^{2}$ Not applicable.

in Italy and that the 2 BTM samplings were performed 6 mo apart, the misidentification of SSP MAP-positive herds by BTM examination, due to seasonal variations, was less likely to occur.

The positivity to BTM ELISA examination was previously correlated with a $\geq 5 \%$ within-herd AP (Arrigoni et al., 2007; Lavers et al., 2014); recently, a correlation between results of repeated tests of bulk tank milk by ELISA and within-herd antibody prevalence was shown by Nielsen and Toft (2014) and, in our study, the correlation between within-herd $\mathrm{AP}$ and $\mathrm{S} / \mathrm{P}$ value was confirmed. This finding is reasonable given that the ELISA tests performed on BTM and individual milk samples have the same target, and that, in herds with a high MAP prevalence of infection, several cows contribute to the antibody titer of BTM (Cazer et al., 2013). This finding may have significant application because it could allow a predictive estimation of the within-herd AP and consequently define priorities for control programs designed to reduce the prevalence of MAP-positive animals.

In-line milk filter positivity by PCR was not significantly associated with the presence of ELISA-positive animals within the herd or with a within-herd $\mathrm{AP} \geq 5 \%$, because PCR detected $58.2 \%$ of herds with a withinherd $\mathrm{AP}<5 \%$ and $61.5 \%$ of herds with a within-herd $\mathrm{AP} \geq 5 \%$ (data not shown).

A few studies have addressed the MAP contamination of ILMF (McKee et al., 2002; Slana et al., 2012; Toth et al., 2013), reporting a wide range of positivity (8.1 to $79.7 \%$ ). The percentage of positive ILMF detected in our study $(10.8 \%)$ was similar to that reported by McKee et al. (2002), who found $8.1 \%$ positive results sampling 2 ILMF from 96 herds. Moreover, our results confirm those of Slana et al. (2012), who reported no association between within-herd prevalence and frequencies of MAP-positive ILMF in herds. No studies are available on the factors affecting ILMF positivity, but studies on BTM showed that milk contamination is more related to the presence of clinical or subclinical high shedders (Sweeney et al., 1992; Boulais et al., 2011; Khol et al., 2013) and milking hygiene (Jayarao et al., 2004) than to within-herd AP itself. On the other hand, ILMF positivity by PCR is a clear index of potential milk contamination, and ILMF analysis can be a useful tool to set priorities in control programs aimed at reducing milk contamination.

The 2 tests combined, PCR on ILMF and ELISA on BTM, detected $85.5 \%$ of positive herds, $92.6 \%$ of herds showing a within-herd AP $\geq 5 \%$, and $100 \%$ of herds showing a within-herd AP $\geq 8.0 \%$. Sergeant et al. (2008) reported that the identification of positive herds based on cultural examination of fecal samples of individual cows was considered too expensive by farmers, and alternative sampling plans based on individual milk sampling or BTM examination were evaluated. For example, Jayarao et al. (2004) reported that single PCR testing of BTM samples had poor sensitivity and low predictive value for MAP detection, whereas Sergeant et al. (2008) evaluated 5 sampling strategies, based on individual fecal culture or milk ELISA of all animals and of selected groups of animals within herds, concluding that individual milk sampling of the whole herd and testing by ELISA was the most costeffective strategy. However, sampling individual milk of the whole herd can be time consuming, expensive, and 
labor intensive for farmers, especially in large herds. In Italy, an ELISA milk test performed using the ID Screen Paratuberculosis indirect confirmation test in the public laboratory of the National Reference Centre for Paratuberculosis costs $€ 2.54$, whereas PCR costs $€ 26.40$, meaning that the complete SSP tested in this study cost $€ 57.88$ for each farm. Testing all lactating animals within a herd by ELISA would exceed the cost of the complete SSP proposed in this study for herds with more than 23 cows. Moreover, the extended milking time and animal stress should be considered additional costs in large herds when the strategy of individual milk sampling of the whole herd is applied. On the other hand, compared with individual milk sampling, the identification of infected herds by the studied SSP yielded little or no information on the proportion of infected animals in herds or on their identification.

\section{CONCLUSIONS}

The proposed SSP was an affordable and useful tool to detect MAP-positive herds with a higher risk of infection diffusion and milk contamination. Although the SSP cannot be used for MAP-free certification of herds, it could be useful to detect heavily infected herds and so prioritize appropriate control measures designed to reduce the prevalence of MAP infection in dairy herds and contamination of milk.

\section{REFERENCES}

APHIS (Animal and Plant Health Inspection Service). 2008. Johne's Disease on US Dairies, 1991-2007: Info sheet. Animal and Plant Health Inspection Service, USDA, Washington, DC. http://www. aphis.usda.gov/animal_health/nahms/dairy/downloads/dairy07/ Dairy07_is_Johnes.pdf.

Arrigoni, N., G. Cammi, I. Losini, R. Taddei, M. Tamba, and G. L. Belletti. 2007. Diagnosis of bovine paratuberculosis: Sensitivity of a commercial ELISA test on bovine bulk milk. Pages 89-90 in Proc. 9th Int. Colloq. Paratuberculosis, Tsukuba, Japan. International Association for Paratuberculosis, Derio, Bizakaia, Spain.

Ayele, W. Y., P. Svastova, P. Roubal, M. Bartos, and I. Pavlik. 2005 Mycobacterium avium subspecies paratuberculosis cultured from locally and commercially pasteurized cow's milk in the Czech Republic. Appl. Environ. Microbiol. 71:1210-1214.

Beard, P. M., M. J. Daniels, D. Henderson, A. Pirie, K. Rudge, D. Buxton, S. Rhind, A. Greig, M. R. Hutchings, I. McKendrick, K. Stevenson, and J. M. Sharp. 2001. Paratuberculosis infection of nonruminant wildlife in Scotland. J. Clin. Microbiol. 39:15171521.

Boulais, C., R. Wacker, J. C. Augustin, M. H. B. Cheikh, and F. Peladan. 2011. Modeling the occurrence of Mycobacterium avium ssp. paratuberculosis in bulk raw milk and the impact of management options for exposure mitigation. J. Food Prot. 74:1126-1136.

Carter, M. A. 2012. Prevalence and prevention of paratuberculosis in North America. Jpn. J. Vet. Res. 60:S9-18.

Carvalho, I. A., P. A. G. Pietralonga, D. G. G. Schwarz, A. C. S. Faria, and M. A. S. Moreira. 2012. Short communication: Recovery of viable Mycobacterium avium subspecies paratuberculosis from retail pasteurized whole milk in Brazil. J. Dairy Sci. 95:6946-6948.
Cazer, C. L., R. M. Mitchell, K. M. Cicconi-Hogan, M. Gamroth, R. M. Richert, P. L. Ruegg, and Y. H. Schukken. 2013. Associations between Mycobacterium avium ssp. paratuberculosis antibodies in bulk tank milk, season of sampling and protocols for managing infected cows. BMC Vet. Res. 9:234.

Cerf, O., M. Griffiths, and F. Aziza. 2007. Assessment of the prevalence of Mycobacterium avium ssp. paratuberculosis in commercially pasteurized milk. Foodborne Pathog. Dis. 4:433-447.

Chiodini, R. J., W. M. Chamberlin, J. Sarosiek, and R. W. McCallum. 2012. Crohn's disease and the mycobacterioses: A quarter century later. Causation or simple association? Crit. Rev. Microbiol. 38:52-93.

Chiodini, R. J., H. J. Van Kruiningen, and R. S. Merkal. 1984. Ruminant paratuberculosis (Johne's disease): The current status and future prospects. Cornell Vet. 74:218-262.

Donaghy, J. A., J. Johnson, and M. T. Rowe. 2011. Detection of Mycobacterium avium spp. paratuberculosis in cheese, milk powder and milk using IS900 and f57-based q-PCR assays. J. Appl. Microbiol. 110:479-489.

Ellingson, J. L. E., J. J. Koziczkowski, and J. L. Anderson. 2005. Detection of viable Mycobacterium avium ssp. paratuberculosis in retail pasteurized whole milk by two culture methods and PCR. J. Food Prot. 68:966-972.

Foddai, A., C. T. Elliott, and I. R. Grant. 2010. Maximizing capture efficiency and specificity of magnetic separation for Mycobacterium avium ssp. paratuberculosis cells. Appl. Environ. Microbiol. 76:7550-7558.

Gardner, I. A., S. S. Nielsen, R. J. Whittington, M. T. Collins, D. Bakker, B. Harris, S. Sreevatsan, J. E. Lombard, R. Sweeney, D. R. Smith, J. Galvachin, and S. Eda. 2011. Consensus-based reporting standard for diagnostic test accuracy studies for paratuberculosis in ruminants. Prev. Vet. Med. 101:18-34.

Gill, C. O., L. Saucier, and W. J. Meadus. 2011. Mycobacterium avium ssp. paratuberculosis in dairy products, meat, and drinking water. J. Food Prot. 74:480-499.

Good, M., T. Clegg, H. Sheridan, D. Yearsely, T. O'Brien, J. Egan, and P. Mullowney. 2009. Prevalence and distribution of paratuberculosis (Johne's disease) in cattle herds in Ireland. Ir. Vet. J. 62:597-606.

Grant, I. R. 2005. Zoonotic potential of Mycobacterium avium ssp. paratuberculosis: The current position. J. Appl. Microbiol. 98:1282-1293.

Grant, I. R. 2006. Mycobacterium avium spp. paratuberculosis in foods: Current evidence and potential consequences. Int. J. Dairy Technol. 59:112-117.

Grant, I. R., H. J. Ball, S. D. Neill, and M. T. Rowe. 1996. Inactivation of Mycobacterium paratuberculosis in cow's milk at pasteurization temperatures. Appl. Environ. Microbiol. 62:631-636.

Grant, I. R., H. J. Ball, and M. T. Rowe. 2002. Incidence of Mycobacterium in bulk raw and commercially pasteurized cow's milk from approved dairy processing establishments in the United Kingdom. Appl. Environ. Microbiol. 68:2428-2435.

Hanifian, S., S. Khani, A. Barzegari, and J. Shayegh. 2013. Quantitative real-time PCR and culture examination of Mycobacterium avium ssp. paratuberculosis at farm level. Vet. Microbiol. 162:160165.

ISO (International Organization for Standardization). 2005. General requirements for the competence of testing and calibration laboratories. ISO/IEC 17025:2005. ISO, Geneva, Switzerland.

Italian Ministry of Health. 2013. Accordo tra il Governo, le Regioni e le Province autonome di Trento e di Bolzano sulle Linee guida per l'adozione dei piani di controllo e certificazione nei confronti della Paratubercolosi bovina. Rep. Atti n. 146/CSR. 17 ottobre 2013. Italian Ministry of Health, Rome, Italy.

Jayarao, B. M., S. R. Pillai, D. R. Wolfgang, D. R. Griswold, C. A Rossiter, D. Tewari, C. M. Burns, and L. J. Hutchinson. 2004. Evaluation of IS900 assay for detection of Mycobacterium avium subspecies paratuberculosis infection in cattle using quarter milk and bulk tank milk samples. Foodborne Pathog. Dis. 1:17-26. 
Kennedy, D. J., and G. Benedictus. 2001. Control of Mycobacterium avium ssp. paratuberculosis infection in agricultural species. Rev. Off. Int. Epizoot. 20:151-179.

Khol, J. L., and W. Baumgartner. 2012a. Examples and suggestion for the control of paratuberculosis in European cattle. Jpn. J. Vet. Res. 60:1-7.

Khol, J. L., and W. Baumgartner. 2012b. Paratuberculosis control in cattle in Europe. Jpn. J. Vet. Res. 60:60-81.

Khol, J. L., M. Wassertheurer, E. Sodoma, S. Revilla-Fernández, J. Damoser, E. Österreicher, M. Dünser, U. Kleb, and W. Baumgartner. 2013. Long-term detection of Mycobacterium avium subspecies paratuberculosis in individual and bulk tank milk from a dairy herd with a low prevalence of Johne's disease. J. Dairy Sci. 96:35173524 .

Lavers, C. J., H. W. Barkema, R. Dohoo, S. L. B. McKenna, and G. P. Keefe. 2014. Evaluation of milk ELISA for detection of Mycobacterium avium subspecies paratuberculosis in dairy herds and association with within-herd prevalence. J. Dairy Sci. 97:299-309.

McKee, R., I. R. Grant, M. T. Rowe, H. G. Buckley, and S. Fanning. 2002. Examination of in-line milk filters to detect Mycobacterium avium ssp. paratuberculosis infection at farm level. Pages 258-260 in Proc. 7th Int. Colloq. Paratuberculosis, Bilbao, Spain. International Association for Paratuberculosis, Derio, Bizakaia, Spain.

Millar, D., J. Ford, J. Sanderson, S. Withey, M. Tizard, T. Doran, and T. J. Hermon. 1996. IS900 PCR to detect Mycobacterium paratuberculosis in retail supplies of whole pasteurized cow's milk in England and Wales. Appl. Environ. Microbiol. 62:3446-3452.

Nielsen, S. S., and N. Toft. 2009. A review of prevalences of paratuberculosis in farmed animals in Europe. Prev. Vet. Med. 88:1-14.

Nielsen, S. S., and N. Toft. 2012. Effect of days in milk and milk yield on testing positive in milk antibody ELISA to Mycobacterium avium ssp. paratuberculosis in dairy cattle. Vet. Immunol. Immunopathol. 49:6-10.

Nielsen, S. S., and N. Toft. 2014. Bulk tank milk ELISA for detection of antibodies to Mycobacterium avium ssp. paratuberculosis: Correlation between repeated tests and within-herd antibody-prevalence. Prev. Vet. Med. 114:96-102.

Nielsen, S. S., N. Toft, and H. Okura. 2013. Dynamics of specific anti-Mycobacterium avium ssp. paratuberculosis antibody response through age. PLoS ONE 8:e63009.

Ricchi, M., R. Taddei, I. Barbieri, G. L. Belletti, M. I. Pacciarini, and N. Arrigoni. 2009. Typing of Mycobacterium avium ssp. paratuberculosis (MAP) strains isolated from different Italian region by four Variable-Number Tandem Repeat (VNTR) methods alone or in association. Pages 60-63 in Proc. 10th Int. Colloq. Paratuberculo- sis, Minneapolis, MN. International Association for Paratuberculosis, Derio, Bizakaia, Spain.

Sergeant, E. S. G., S. S. Nielsen, and N. Toft. 2008. Evaluation of test-strategies for estimating probability of low prevalence of paratuberculosis in Danish dairy herds. Prev. Vet. Med. 85:92-106.

Shankar, H., S. V. Singh, P. K. Singh, A. V. Singh, J. S. Sohal, and R. J. Greenstein. 2010. Presence, characterization, and genotype profiles of Mycobacterium avium subspecies paratuberculosis from unpasteurized individual and pooled milk, commercial pasteurized milk, and milk products in India by culture, PCR, and PCE-REA methods. Int. J. Infect. Dis. 14:121-126.

Slana, I., P. Kralik, A. Kralova, V. Babak, and I. Pavlik. 2012. Short communication: Examination of milk filters by real-time PCR as a herd-level indicator of the presence of Mycobacterium avium subspecies paratuberculosis in dairy herds. J. Dairy Sci. 95:1162-1165.

Slana, I., M. Liapi, M. Moravkova, A. Kralova, and I. Pavlik. 2009. Mycobacterium avium ssp. paratuberculosis in cow bulk tank milk in Cyprus detected by culture and quantitative IS900 and F57 real-time PCR. Prev. Vet. Med. 89:223-226.

Stephan, R. K. Bohler, and S. Corti. 2002. Incidence of Mycobacterium avium subspecies paratuberculosis in bulk-tank milk samples from different regions in Switzerland. Vet. Rec. 150:214-215.

Sung, N., and M. T. Collins. 1998. Thermal tolerance of Mycobacterium paratuberculosis. Appl. Environ. Microbiol. 64:999-1005.

Sweeney, R. W., R. H. Whitlock, and A. E. Rosenberger. 1992. Mycobacterium paratuberculosis cultured from milk and supramammary lymph nodes of infected asymptomatic cows. J. Clin. Microbiol. 30:166-171.

Toth, J. D., H. W. Aceto, S. C. Rankin, and Z. Dou. 2013. Short communication: Survey of animal-borne pathogens in the farm environment of 13 dairy operations. J. Dairy Sci. 96:5756-5761.

Van Brandt, L., I. Van der Plancken, J. De Block, G. Vlaemynck, E. Van Coillie, L. Herman, and M. Hendrickx. 2011. Adequacy of current pasteurization standards to inactivate Mycobacterium paratuberculosis in milk and phosphate buffer. Int. Dairy J. 21:295-304

van Weering, H., G. Van Schaik, A. Van der Meulen, M. Waal, P. Franken, and K. Van Maanen. 2007. Diagnostic performance of the Pourquier ELISA for detection of antibodies against Mycobacterium avium subspecies paratuberculosis in individual milk bulk samples of dairy herds. Vet. Microbiol. 125:49-58.

Wilson, D. J., K. Rood, P. Biswas, and T. M. Byrem. 2010. Herd-level prevalence of Johne's disease in Utah and adjacent areas of the Intermountain West as detected by a bulk-tank milk surveillance project. J. Dairy Sci. 93:5792-5797. 